\title{
Evaluation of Muscle Tension in Hemiplegia Patients with a Real-time Monitoring System during High Intensity Laser Therapy
}

\author{
Sang-Kwan Lee ${ }^{1}$, Hyeong-O Lee ${ }^{2}$, and Jong-In Youn ${ }^{2} *$ \\ ${ }^{I}$ Department of Internal Medicine and Neuroscience, College of Oriental Medicine, \\ Wonkwang University, Iksan 570-749, Korea \\ ${ }^{2}$ Department of Biomedical Engineering, Catholic University of Daegu, Gyeongsan 712-702, Korea
}

(Received February 24, 2015 : revised April 17, 2015 : accepted May 6, 2015)

\begin{abstract}
In this study, we evaluated the muscle tension in hemiplegia patients using a real-time monitoring system combined with high-intensity laser treatment (HILT) device. Five hemiplegia patients were treated with HILT in the left forearm muscle for 8 minutes, and the muscle was relaxed for 8 minutes following the treatment. Both the gradient of the force-displacement curves and the muscle hardness decreased during the therapy, and the effects were maintained following the treatment. The results show that muscle tension decreased rapidly during laser irradiation, and the efficacy of the treatment depended on the duration of the illness. Consequently, we conclude that this combined HILT and real-time muscle tension monitoring system is useful for evaluating the therapeutic procedure and for treatment of muscle pain.
\end{abstract}

Keywords : Hemiplegia, High intensity laser therapy, Real-time monitoring, Muscle tension

OCIS codes : (170.0170) Medical optics and biotechnology; (170.1610) Clinical applications; (170.3890)

Medical optics instrumentation

\section{INTRODUCTION}

Hemiplegia is a common symptom following stroke [1]. The most significant symptom of hemiplegia following stroke is problems with movement due to muscle tension. Alleviation and evaluation of muscle tension is important in rehabilitation of hemiplegia patients [2]. Two terms are commonly used to identify muscle tension: muscle tone and muscle spasm. Muscle tone is defined as the resistance to a passive stretch that reflects the relative influence of the mechanical-elastic characteristics and reflexive drive to the muscle. Muscle spasm is defined as the velocity-dependent resistance to passive stretching, and is accompanied by increased deep tendon reflexes $[3,4]$.

Several tools have been used to treat muscle tension, including drugs, Botox, electrical stimulation therapy, and surgery. However, these methods may also affect normal muscle $[5,6]$. Laser therapy is a novel therapy which has been used to treat rheumatoid arthritis, chronic pain and muscle strain [7]. Laser therapy can be divided into two categories: low-level laser therapy (LLLT) and high-intensity laser therapy (HILT), depending on the laser fluence. Lopes-
Martins et al. [8] reported that LLLT doses of 0.5 and 1.0 $\mathrm{J} / \mathrm{cm}^{2}$ could prevent the development of muscular fatigue in rats during repeated tetanic contractions, and Leal et al. [9] reported that LLLT appeared to delay the onset of muscle fatigue and exhaustion via a local mechanism despite increased blood lactate levels. Despite these positive effects, the low power density of the laser limits its penetration into the muscle tissue, so that the application of LLLT is restricted to superficial tissue. However, HILT uses a higher intensity laser irradiation, which results in minor and slow light absorption by chromophores. Absorption occurs not with concentrated light, but with scattered light. Therefore, a high-power laser may reach deep tissue without cellular damage, and may be used to treat deep joints and deep muscles, which are difficult to reach using conventional lasers [10-12]. The absorbed light stimulates cell metabolism, leading to photochemical effects and raising the temperature of deep tissues. Such laser-tissue interactions trigger the lymphatic system and increase microcirculation [13].

There are several methods that can be used to evaluate muscle tension, including the modified Ashworth scale (MAS), tone assessment scale (TAS), electromyography (EMG),

\footnotetext{
*Corresponding author: jyoun@cu.ac.kr

Color versions of one or more of the figures in this paper are available online.
} 
and the Myotonometer. The MAS is a six-point ordinal scale for grading the resistance encountered during passive muscle stretching. It includes a $1+$ scoring grade to indicate resistance through less than half of the movement [14]. Because MAS does not take account of the relation between abnormal tone and posture and the associated reaction, TAS was developed to address these issues that may be important with the measurement of tone and its impact on function [15-17]. However, Gergson et al. [18] reported that TAS is not reliable for measuring posture and associated reactions, due to limited accuracy for the ankle joint. EMG is a technique for evaluating and recording the electrical activity of skeletal muscles. It detects the electric potential generated by muscle cells when these cells are electrically or neurologically activated [19]. Because it measures the electrical signals in muscle cells at the surface of the skin, it may not provide much information about the deep muscle tissue. The Myotonometer is a computerized, electronic tissue compliance meter that is capable of noninvasive assessment of muscle tone and stiffness, both at rest and during contractions. The Myotonometer data obtained from a relaxed muscle provide a direct measure of resting tone or stiffness of the muscle, and the underlying tissues. Data obtained during muscle contraction provide an indirect and valid measurement of muscle strength [20].

We have previously [21] reported a real-time monitoring system using the Myotonometer for HILT, and demonstrated a muscle tension release effect in normal subjects. The muscle tension is characterized using the muscle hardness; i.e., $[22]$

$$
E=I d\left(1-\mu^{2}\right)\left(y x^{-1}\right),
$$

where $\mathrm{I}$ is the influence coefficient, $\mathrm{d}$ is the radius of the Myotonometer rod, $\mu$ is Poisson's ratio, $x$ is the displacement, and $y$ is the force. In this work, we use this monitoring system for hemiplegia patients to demonstrate the therapeutic effect of HILT in muscle spasm following a stroke.

\section{MATERIALS AND METHODS}

The subjects were recruited from the Oriental Medical Clinic at WonKwang University Oriental Medicine Hospital in Gwangju, and ethical approval was obtained from the Ethics Committees of the hospital. All patients had hemiplegia following a stroke, and had MAS grades in the range 1-2. The mean age of the subjects was 58.4 years (the age range was 37-75 years), and they comprised two males and three females. Table 1 lists data describing the subjects of this study.

\subsection{Real-time Monitoring System}

We have previously combined HILT and the Myotonometer to create a real-time feedback monitoring and treatment
TABLE 1. Data on the patients

\begin{tabular}{c|c|c|c|c}
\hline \hline & $\begin{array}{c}\text { Duration of } \\
\text { illness } \\
\text { (month) }\end{array}$ & Age (year) & Gender & MAS \\
\hline CASE 1 & 8 & 49 & $\mathrm{~F}$ & 2 \\
\hline CASE 2 & 11 & 75 & $\mathrm{~F}$ & 1 \\
\hline CASE 3 & 22 & 37 & $\mathrm{M}$ & 2 \\
\hline CASE 4 & 30 & 72 & $\mathrm{~F}$ & 2 \\
\hline CASE 5 & 72 & 59 & $\mathrm{M}$ & 2 \\
\hline
\end{tabular}

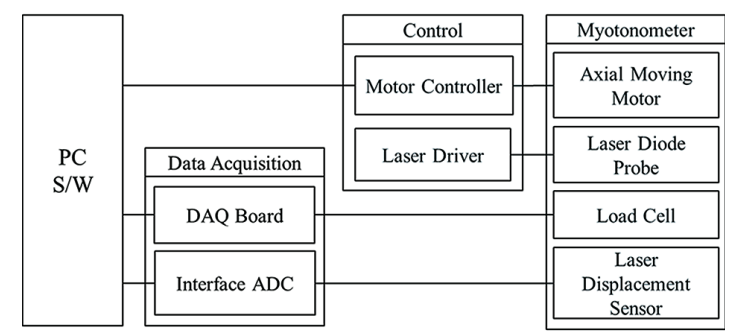

FIG. 1. The experimental layout of the monitoring system.

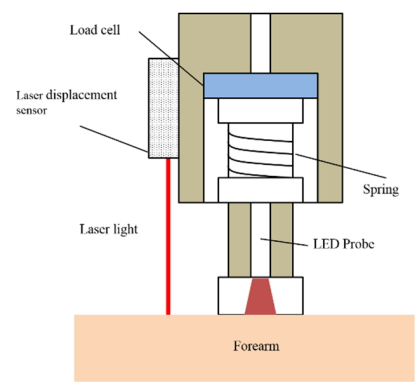

(a)

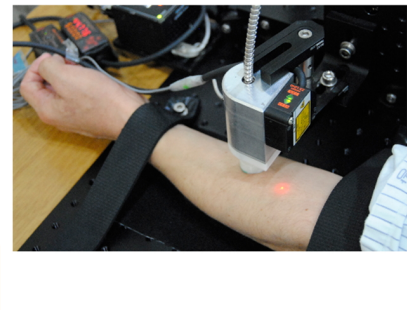

(b)
FIG. 2. (a) A schematic diagram and (b) a photograph of the combined HILT-Myotonometer probe.

system [21]. The composition of the monitoring system and HILT-Myotonometer system is shown schematically in Figs. 1 and 2. Figure 1 shows the moving motor and moving controller, which were used for linear control of the velocity of the Myotonometer during the measurements. The 808-nm high-power diode laser had a spot size of $0.07 \mathrm{~cm}^{2}$, and the irradiance was $4.28 \mathrm{~W} / \mathrm{cm}^{2}$; the beam was focused using a bi-concave lens to vary the spot size in the range $0.07-1$ $\mathrm{cm}^{2}$ to irradiate a larger area, and increase the therapeutic effect. The laser diode probe was placed in the center of the Myotonometer, which enables us to measure muscle tension continuously and in real-time during the laser therapy. When the Myotonometer was pressed vertically onto the patient's skin, a load cell (LTH 3000, FUTEK, USA) was used to measure the pressure, and a laser displacement sensor (ZX-LD40, OMRON, JAPAN) was used to measure the distance. To reduce error incurred by the concave 


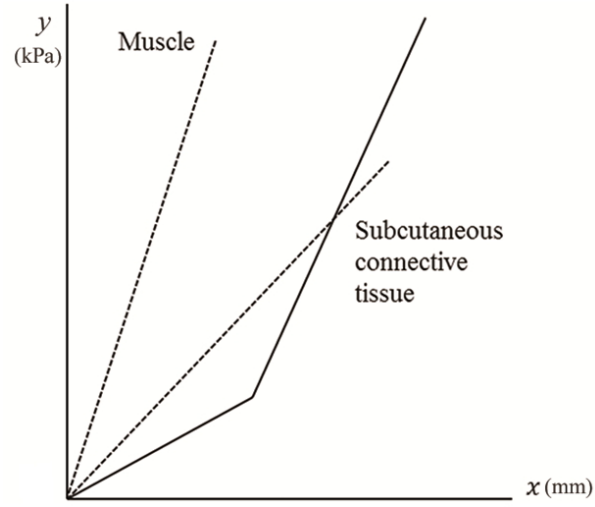

(a)

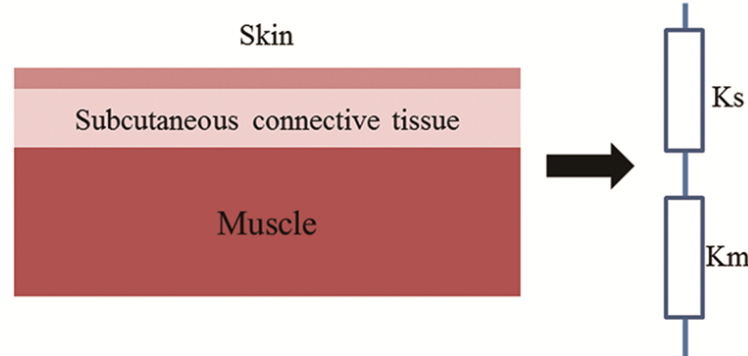

(b)

FIG. 3. (a) Hardness of subcutaneous and muscle tissue. ${ }^{21}$ The displacement is plotted on the $\mathrm{x}$-axis and the pressure on the $\mathrm{y}$-axis to obtain a pressure-displacement curve. Gradient of this curve gives the hardness in $\mathrm{kPa} / \mathrm{mm}$. (b) A schematic diagram showing the elastic tissue in the human body and a two-layer spring model.

depression, which may result when the load cell is close to the surface of the skin, the load cell was placed $5 \mathrm{~cm}$ from the laser displacement sensor [22]. The output signals were collected using a data acquisition board (USB-6210, National Instruments) interfacing with an analog-to-digital converter, and the muscle stiffness was calculated from the ratio of the changes in distance and pressure. After applying pressure to the surface of the skin, the displacement was measured to determine hardness of the muscle, as shown in Fig. 3(a). The pressure from the Myotonometer was applied separately to the subcutaneous connective tissue and the muscle tissue. In the early stages of the pressure-displacement curve, we find a relatively small gradient, which corresponds to a small hardness of the soft subcutaneous connective tissue. During the later stages, however, the hardness increased, due to the larger stiffness of the muscle tissue. This behavior can be described using a two-layer spring model, as shown in Fig. 3(b) [23]. With this two-layer spring model, the force-displacement relation in the early stages of displacement is given by

$$
f=\frac{K_{s} \times K_{m}}{K_{s}+K_{m}} \chi
$$

where $\mathrm{f}$ is the force due to the pressure applied at the terminal, $K_{s}$ is the stiffness of skin and subcutaneous connective tissues, $K_{m}$ is the stiffness of the muscle, and $\chi$ is the displacement.

\subsection{Treatment Procedure}

The left forearm was investigated. All patients underwent both the active and post-treatment tests. An 808-nm diode laser $\left(\mathrm{CW}\right.$ mode, $0.07-\mathrm{cm}^{2}$ spot size, and average power of $4.28 \mathrm{~W} / \mathrm{cm}^{2}$ ) was used during the active test, and the patients relaxed without any stimulus during the post-treatment test. Each phase of the test lasted 8 minutes, and the force and displacement were measured every 2 minutes during treatment,

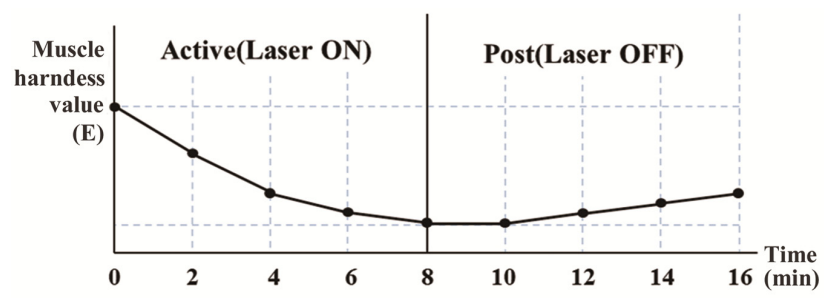

FIG. 4. Schematic diagram showing the muscle tension level as a function of time during laser treatment.

as shown in Fig. 4. The post-treatment test was performed to monitor the relief of muscle tension and the duration of the effect following HILT. This may supplement the positive effects of laser treatment. To determine the location of the Myotonometer probe, a circle corresponding to the diameter of the probe tip was marked on the surface of the skin.

\subsection{Muscle Tension Measurements}

To evaluate a degree of muscle tension, the gradient of the force-displacement graph and the muscle hardness $\mathrm{E}$ were analyzed. In the force-displacement curves, the force was determined based on the input voltage of the load cell, ${ }^{21}$ and the displacement was found to increase in proportion to this force, which was applied to the subcutaneous tissue; however, the gradient of the force-displacement curve depended on the degree of muscle tension. Using the measured force and displacement during laser treatment, we calculated the muscle hardness using Eq. (1), which represents the change in muscle tension as a function of time.

\section{RESULTS AND DISCUSSION}

To establish treatment procedure and to evaluate the results, it is important to accurately monitor the variation in the skeletal muscle. Conventional evaluation methods, 
including MAS and EMG, are generally reliable; however, they do not provide information on the muscle tension [24]. The experiments described in the study were designed for in vivo evaluation of muscle hardness during HILT using a Myotonometer.

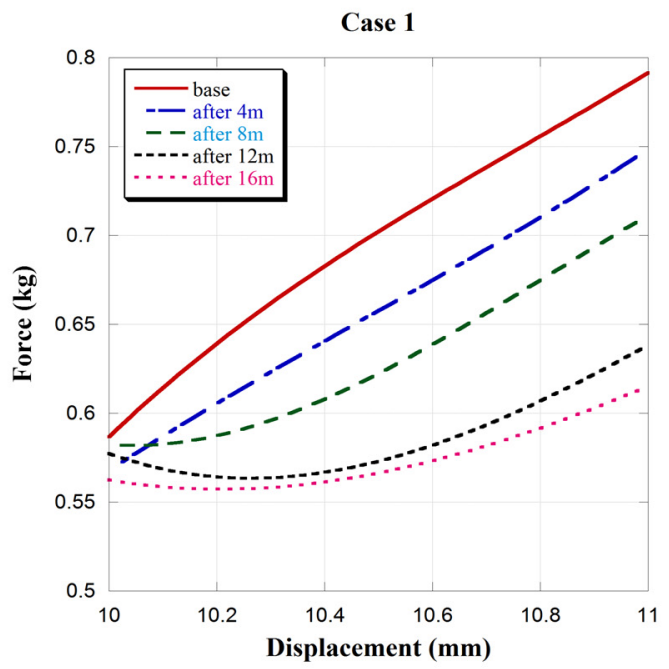

Case 3

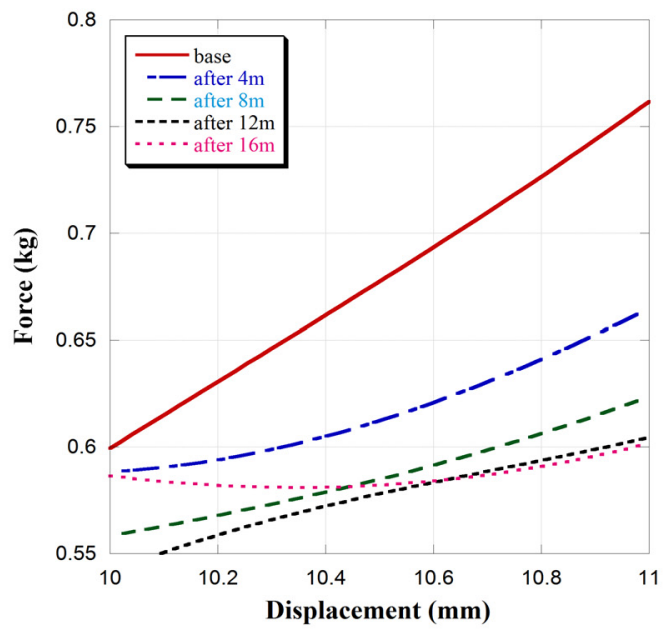

Case 5

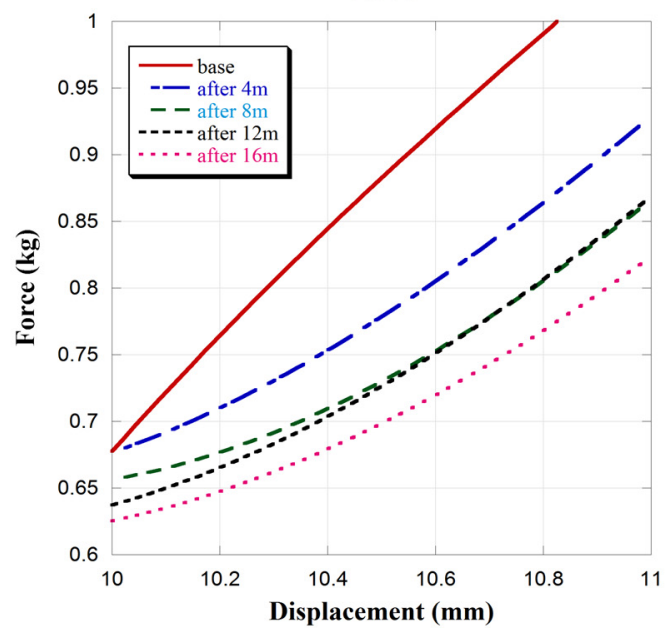

\subsection{Force-displacement Measurements}

Figure 5 shows force-displacement curves for the five patients measured every 2 minutes. Some data were lost due to unexpected movements during measurement (especially with case 3). Each curve corresponds to a degree of muscle

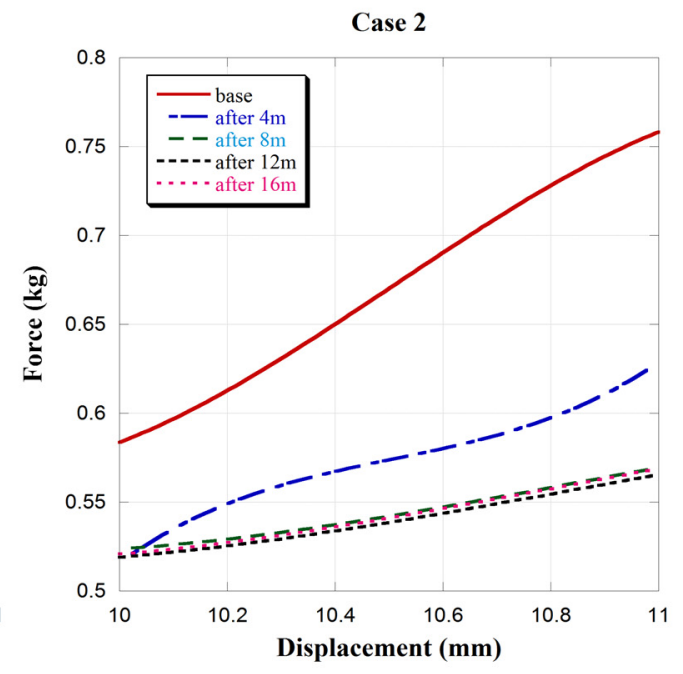

Case 4

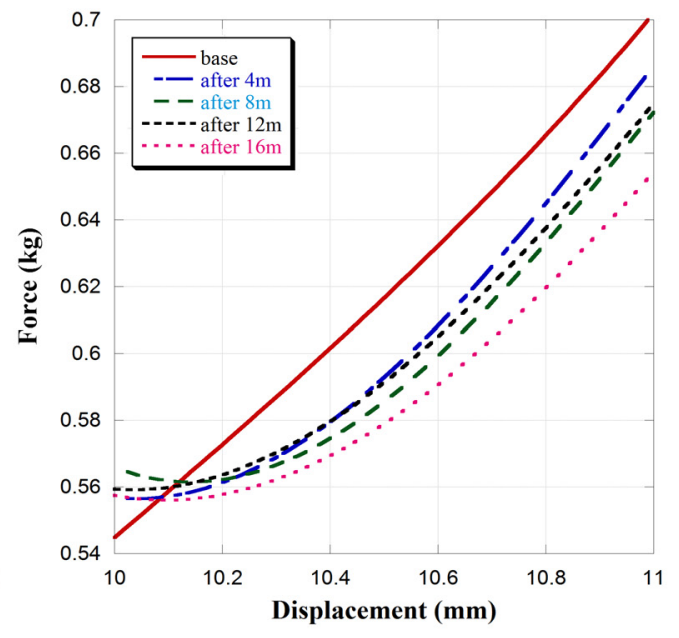

FIG. 5. Force-displacement curves of the five hemiplegia patients. 
resistance when specific force $(0.5-1 \mathrm{~kg})$ was applied on the surface of the skin. Hemiplegic patients have stiffer muscles with more non-uniform muscle fibers and with a shorter muscle fiber length, and these abnormalities lead to increased passive stiffness [21-27]. As a consequence, the abnormal muscle tissue resulted in lower resistance, and the displacement per unit force is in inverse proportion to muscle stiffness.

The force required to change the displacement was highest in the base state; i.e., before-treatment state, and gradually reduced during laser irradiation, with the effect being maintained for some time following the treatment. The required force changed more significantly during the active phase of the experiments than during the post-treatment phase. Moreover, not only did the required force change but also the gradient of the force-displacement curve varied during the experiments. During the active part of the test, the gradient decreased; however, the gradient then increased during the post-treatment phase, although the required force remained smaller than prior to the therapy. These results indicate that muscle tension decreased during the treatment, and slowly recovered following the treatment.

\subsection{Muscle Hardness}

The muscle hardness may be calculated from the displacement and the applied force using Eq. (1). The muscle hardness $\mathrm{E}$ corresponds to the gradient of the force-displacement curve. The value of $\mathrm{E}$ may be used to characterize the therapeutic effect of HILT on muscle hardness. Table 2 lists $\mathrm{E}$ as a function of time during treatment, and Fig. 6 shows these data normalized to the initial (i.e., pre-treatment) value of $\mathrm{E}$. We find that $\mathrm{E}$ decreased as a function of time during the active treatment phase (i.e., with laser radiation), and that this reduction in $\mathrm{E}$ was preserved during the post-treatment phase (albeit with some increase). This shows that HILT had a therapeutic effect that persisted following the application of the therapy. Although the same protocol was applied to all patients, there was some variation in

TABLE 2. The muscle hardness E during each test

\begin{tabular}{c|c|c|c|c|c|c}
\hline \hline & $\begin{array}{c}\text { Measurement time } \\
(\mathrm{m})\end{array}$ & Case 1 & Case 2 & Case 3 & Case 4 & Case 5 \\
\hline \multirow{4}{*}{ Active Test } & 0 & 2.24 & 1.59 & 1.94 & 2.10 & 0.47 \\
\cline { 2 - 7 } & 2 & 1.61 & 1.06 & 1.09 & 1.74 & 0.35 \\
\cline { 2 - 7 } & 4 & 1.87 & 1.04 & 1.36 & 1.65 & 0.36 \\
\cline { 2 - 7 } & 6 & 0.83 & 0.49 & 1.03 & 1.54 & 0.34 \\
\cline { 2 - 7 } & 8 & 1.25 & 0.35 & 1.02 & 1.61 & 0.34 \\
\cline { 2 - 7 } & 10 & 1.55 & 0.26 & 0.82 & 1.67 & 0.35 \\
\cline { 2 - 7 } & 12 & 1.67 & 0.38 & 0.92 & 1.82 & 0.33 \\
\cline { 2 - 7 } & 14 & 1.33 & 0.26 & 0.86 & 1.71 & 0.32 \\
\hline
\end{tabular}

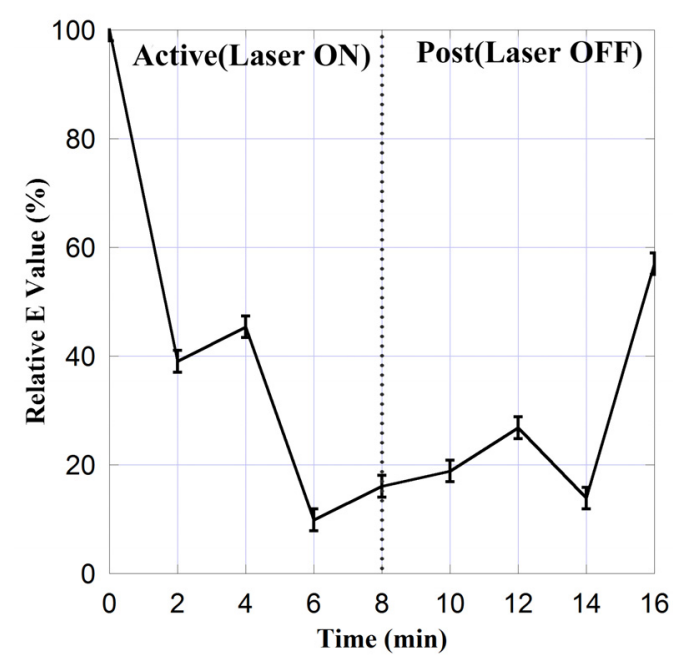

FIG. 6. The average relative muscle hardness $E_{R}=E_{t}$ $/ E_{0} \times 100$, where $\mathrm{E}_{\mathrm{t}}$ is the muscle hardness at a given measurement time and $\mathrm{E} 0$ is the baseline muscle hardness.

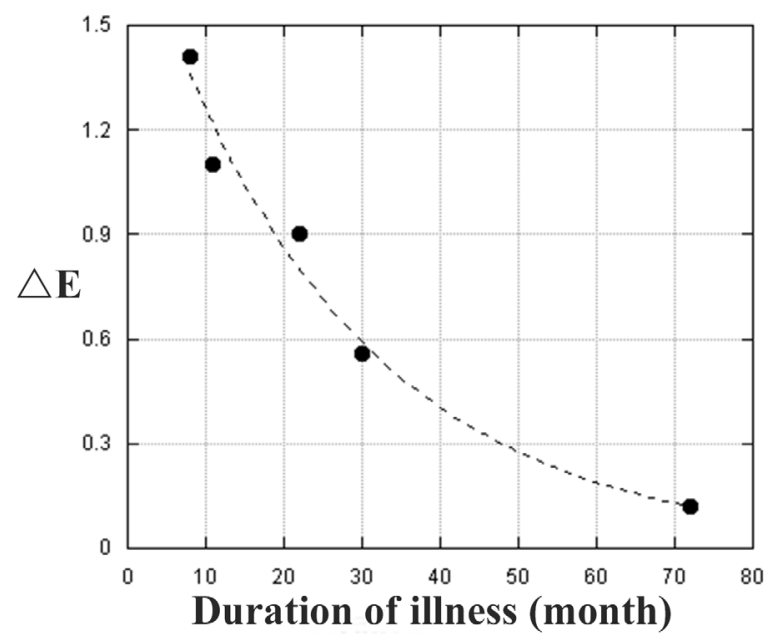

FIG. 7. The magnitude of the changes in muscle hardness $E$ as a function of the duration of the illness. 
therapeutic effect between patients. Some patients exhibited a tendency for $\mathrm{E}$ to return to the initial state, whereas with case 2 (75 years, MAS 1) the low muscle stiffness was maintained. These inter-patient variations are attributed biological and pathological characteristics of the muscle cells in each patient. [28] In addition, slower muscle recovery from stimuli may be expected in older patients [29].

The variations in muscle hardness (E) depending on the duration of illness are shown in Fig. 7 to evaluate the treatment efficacy. A larger variation in E corresponds to the more effective treatment. We found that the treatment efficacy decreased exponentially as a function of the duration of illness. Some studies have reported a similar drop in efficacy as a function with the duration of the illness [30-33]. Recovery of muscle function has been shown to be the most significant during the first week after stroke, and rehabilitation is less effective when initiated more than 3 months after a stroke [30]. It has also been reported that the most significant factor affecting treatment efficacy is not the severity of the muscle tension, rather the duration of the illness [31-33]. Moreover, the ceiling effect; i.e., an increasing dose of a given medication or treatment having progressively smaller effect, may affect the efficacy of treatment [34-37].

We found that force-displacement decreased exponentially during laser treatment, and the HILT effect was maintained following the therapy. The muscle hardness, which was determined from the gradients of the force-displacement curves, decreased during laser irradiation and the low muscle tension was maintained following the treatment.

\section{CONCLUSION}

HILT is a non-invasive therapy that can be used for treating muscle disorders, and the Myotonometer is a reliable tool for assessing muscle stiffness, tone, and compliance. In this study, we combined HILT and Myotonometer measurements to achieve simultaneous laser treatment and real-time monitoring, and this combined system allowed quantitative measurements of the treatment efficacy during the therapy. HILT exerted a positive effect in relieving muscle tension in hemiplegic patients. We quantitatively evaluated the muscle tension using force-displacement curves to determine the muscle hardness. The treatment efficacy was lower in patients where the duration of illness was longer. This real-time monitoring and treatment system can be helpful in developing treatment strategies to avoid ceiling effects and to increase the treatment efficacy.

\section{ACKNOWLEDGMENT}

This research was supported by Basic Science Research Program through the National Research Foundation of Korea (NRF) funded by the Ministry of Education, Science and
Technology (2010-0008977, 2010-0029468) and a grant of the Traditional Korean Medicine R\&D Project, Ministry for Health \& Welfare \& Family Affairs, Republic of Korea (B110010)

\section{REFERENCES}

1. B. H. Dobkin, "The rehabilitation of elderly stroke patients," Clin. Geriatr. Med. 7, 507-523 (1991).

2. H. Li, G. Zhao, Y. Zhou, X. Chen, Z. Ji, and L. Wang, "Relationship of EMG/SMG features and muscle strength level: an exploratory study on tibialis anterior muscles during plantar-flexion among hemiplegia patients," Biomed. Eng. Online 13, 5 (2014).

3. D. Simons and S. Mense, "Understanding and measurement of muscle tone as related to clinical muscle pain," Pain $\mathbf{7 5}$, 1-17 (1998).

4. C. T. Leonard, J. U. Stephens, and S. L. Stroppel, "Assessing the spastic condition of individuals with upper motoneuron involvement: validity of the myotonometer," Arch. Phys. Med. Rehabil. 82, 1416-1420 (2001).

5. H. Park, Z. Lee, and Y. Lee, "Thee effective intensive functional electrical stimulation on the gait in chronic hemiplegic patients," Korean. J. Clin. Neurophysiol. 7, 13-16 (2005).

6. B. Knost, H. Flor, N. Birbaumer, and M. M. Schugens, "Learned maintenance of pain: Muscle tension reduces central nervous system processing of painful stimulation in chronic and subchronic pain patients," Psychophysiology 36, 755-764 (1999).

7. L. Walsh, "The current status of low level laser therapy in dentistry, Part 1. Soft tissue applications," Aust. Dent. J. 42, 247-254 (1997).

8. R. Á B. Lopes-Martins, R. L. Marcos, P. S. Leonardo, A. C. Prianti, M. N. Muscará, F. Aimbire, L. Frigo, V. V. Iversen, and J. M. Bjordal, "Effect of low-level laser (Ga-Al-As $655 \mathrm{~nm}$ ) on skeletal muscle fatigue induced by electrical stimulation in rats," J. Appl. Physiol. 101, 283-288 (2006).

9. E. C. Leal Junior, R. Á B. Lopes-Martins, F. Dalan, M. Ferrari, F. M. Sbabo, R. A. Generosi, B. M. Baroni, S. C. Penna, V. V. Iversen, and J. M. Bjordal, "Effect of 655-nm low-level laser therapy on exercise-induced skeletal muscle fatigue in humans," Photomed. Laser. Surg. 26, 419-424 (2008).

10. A. Santamato, V. Solfrizzi, F. Panza, G. Tondi, V. Frisardi, B. G. Leggin, M. Ranieri, and P. Fiore, "Short-term effects of high-intensity laser therapy versus ultrasound therapy in the treatment of people with subacromial impingement syndrome: a randomized clinical trial," Phys. Ther. 89, 643-652 (2009).

11. R. X. D. Nascimento and F. Callera, "Low-level laser therapy at different energy densities $\left(0.1-2.0 \mathrm{~J} / \mathrm{cm}^{2}\right)$ and its effects on the capacity of human long-term cryopreserved peripheral blood progenitor cells for the growth of colonyforming units," Photomed. Laser. Surg. 24, 601-604 (2006).

12. A. A. M. Thabet, M. S. E. Mohamed, M. M. I. Ali, and O. F. Helal, "High intensity laser versus low itensity laser therapy in management of postmenopausal osteoporosis," 
Energy for Health 10, 16-21 (2013).

13. N. Stiglic-Rogoznica, D. Stamenkovic, L. Frlan-Vrgoc, V. Avancini-Dobrovic, and T. S. Vrbanic, "Analgesic effect of high intensity laser therapy in knee osteoarthritis," Coll. Antropol. 35, 183-185 (2011).

14. R. W. Bohannon and M. B. Smith, "Interrater reliability of a modified Ashworth scale of muscle spasticity," Phys. Ther. 67, 206-207 (1987).

15. B. Taylor, E. Ellis, and D. Haran, "The reliability of measurement of postural alignment to assess muscle tone change," Physiotherapy 81, 485-490 (1995).

16. A. A. Mullick, M. K. Musampa, A. G. Feldman, and M. F. Levin, "Stretch reflex spatial threshold measure discriminates between spasticity and rigidity," Clin. Neurophysiol. 124, 740-751 (2013).

17. Z. Dvir and E. Panturin, "Measurement of spasticity and associated reactions in stroke patients before and after physiotherapeutic intervention," Clin. Rehabil. 7, 15-21 (1993).

18. J. M. Gregson, M. Leathley, A. P. Moore, A. K. Sharma, T. L. Smith, and C. L. Watkins, "Reliability of the Tone Assessment Scale and the modified Ashworth scale as clinical tools for assessing poststroke spasticity," Arch. Phys. Med. Rehabil. 80, 1013-1016 (1999).

19. G. Kamen, "Electromyographic kinesiology," Research Methods in Biomechanics.Human Kinetics Publ., Champaign (2004).

20. C. T. Leonard and E. L. Mikhailenok, "Apparatus for measuring muscle tone," US Patent 6,063,044 (2000).

21. J. Hong and J. Youn, "Development of real-time monitoring system for muscle tension by high intensity laser therapy," J. Biomed. Eng. Res. 33, 128-134 (2012).

22. M. Murayama, K. Nosaka, T. Yoneda, and K. Minamitani, "Changes in hardness of the human elbow flexor muscles after eccentric exercise,” Eur. J. Appl. Physiol. 82, 361-367 (2000)

23. M. Horikawa, S. Ebihara, F. Sakai, and M. Akiyama, "Noninvasive measurement method for hardness in muscular tissues," Med. Biol. Eng. Comput. 31, 623-627 (1993).

24. R. T. Katz and W. Z. Rymer, "Spastic hypertonia: mechanisms and measurement," Arch. Phys. Med. Rehabil. 70, 144-155 (1989).

25. J. Rose, W. L. Haskell, J. G. Gamble, R. L. Hamilton, D. A. Brown, and L. Rinsky, "Muscle pathology and clinical measures of disability in children with cerebral palsy," J. Orthop. Res. 12, 758-768 (1994).

26. T. Sinkjaer and I. Magnussen, "Passive, intrinsic and reflexmediated stiffness in the ankle extensors of hemiparetic patients," Brain 117 (Pt 2), 355-363 (1994).

27. C. Tardieu, E. Huet de la Tour, M. D. Bret, and G. Tardieu, "Muscle hypoextensibility in children with cerebral palsy: I. Clinical and experimental observations," Arch. Phys. Med. Rehabil. 63, 97-102 (1982).

28. J. Fridén and R. L. Lieber, "Spastic muscle cells are shorter and stiffer than normal cells," Muscle Nerve 27, 157-164 (2003).

29. J. A. Kent-Braun, D. M. Callahan, J. L. Fay, S. A. Foulis, and J. P. Buonaccorsi, "Muscle weakness, fatigue, and torque variability: effects of age and mobility status," Muscle Nerve 49, 209-217 (2014).

30. R. Formisano, P. Pantano, M. G. Buzzi, V. Vinicola, F. Penta, P. Barbanti, and G. L. Lenzi, "Late motor recovery is influenced by muscle tone changes after stroke," Arch. Phys. Med. Rehabil. 86, 308-311 (2005).

31. P. Burbaud, L. Wiart, J. L. Dubos, E. Gaujard, X. Debelleix, P. A. Joseph, J. M. Mazaux, B. Bioulac, M. Barat, and A. Lagueny, "A randomised, double blind, placebo controlled trial of botulinum toxin in the treatment of spastic foot in hemiparetic patients," J. Neurol. Neurosurg. Psychiatry. 61, 265-269 (1996).

32. A. Suputtitada, "Local botulinum toxin type A injections in the treatment of spastic toes," Am. J. Phys. Med. Rehabil. 81, 770-775 (2002).

33. L. Ramos, L. Junior, E. C. Pinto, R. C. Pallotta, L. Frigo, R. L. Marcos, M. H. de Carvalho, J. M. Bjordal, and R. Á B. Lopes-Martins, "Infrared $(810 \mathrm{~nm})$ low-level laser therapy in experimental model of strain-induced skeletal muscle injury in rats: effects on functional outcomes," Photochem. Photobiol. 88, 154-160 (2012).

34. P. Duncan, S. Lai, R. Bode, S. Perera, and J. DeRosa, "Stroke Impact Scale-16: A brief assessment of physical function," Neurology 60, 291-296 (2003).

35. C. T. Leonard, W. P. Deshner, J. W. Romo, E. S. Suoja, S. C. Fehrer, and E. L. Mikhailenok, "Myotonometer intra-and interrater reliabilities," Arch. Phys. Med. Rehabil. 84, 928-932 (2003).

36. F. Sakai, S. Ebihara, M. Akiyama, and M. Horikawa, "Pericranial muscle hardness in tension-type headache: A non-invasive measurement method and its clinical application," Brain 118, 523-531 (1995).

37. B. D. Steinberg, "Evaluation of limb compartments with increased interstitial pressure. An improved noninvasive method for determining quantitative hardness," J. Biomech. 38, 1629-1635 (2005). 